\title{
Extinction reversal by Scopolamine
}

W. F. HERBLIN, Central Research Department, ${ }^{1}$ Experimental Station, E. I. du Pont de Nemours and Company, Wilmington, Delaware

Rats were trained to discriminate right from left in a dual lever situation and bar-press for a food reward. An extinction situation was then established by discontinuing the food reward. When behavioral extinction had been accomplished as judged by the performance of the animals, injections of scopolamine hydrobromide resulted in a large increase in bar-pressing which was selective for the side on which the animal was originally trained.

Several investigators have shown that scopolamine hydrobromide will increase resistance to extinction of an operant response such as bar pressing when injected at the start of extinction trials (Herrnstein, 1958; Carlton, 1963). It became of interest, however, to determine whether scopolamine hydrobromide would induce the recovery of an operant response which had been previously extinguished. In view of the mild stimulatory effects of the drug, a discrimination task seemed the most appropriate choice. In this way, recovery of the operant response could possibly be separated from an increase in general activity.

\section{SUBJECTS}

Fifteen female Holtzman rats, three months old at the start of the experiment, were maintained at approximately $180 \mathrm{~g}$ or $90 \%$ of their initial weight.

\section{APPARATUS}

A model A-100 rodent cage measuring $9-1 / 2 \times 8 \times 8-5 / 8$ in was fitted with a food cup in the center of one end and two levers, one on each side of the food cup. A pellet dispenser was fitted to the food cup to deliver $45 \mathrm{mg}$ Noyes food pellets. Responses were monitored automatically on reed relay equipment. All of the apparatus was obtained from the Scientific Prototype Corporation of New York.

\section{PROCEDURE}

Ss were divided randomly into three groups of five animals each and designated right, left, and control. Each animal was placed in the training box for a 10 min session on Days 1 and 2 , two separate 10-min sessions on Days 3,4 , and 5 , and one final 10-min session on Day 6. During these training sessions, rats in the left and right groups were given one pellet for each correct response and rats in the control group were given one pellet every $20-40 \mathrm{sec}$.

The response was extinguished by placing each animal in the training box for two separate 10-min sessions per day on Days 9-17 with the reward circuitry inoperative. The animals therefore were denied both reward and secondary reinforcers such as the sound of the pellet dispenser.

Animals received subcutaneous injections of $0.32 \mu \mathrm{g}$ scopolamine hydrobromide on Day $18,3.2 \mu \mathrm{g}$ on Day 21,32 $\mu \mathrm{g}$ on Day 24 , saline on Days 30 and 32 , and $32 \mu \mathrm{g}$ scopolamine $\mathrm{HBr}$ on Day 39, and were tested without injection on Day 44. Each animal was given a 5 -min test session at $0.5,1.0,1.5$, and $2.0 \mathrm{~h}$ after injection. Test sessions were identical with extinction trials except for the shorter duration.

Derived scores were obtained by subtracting the responses on the left-hand lever from those on the right-hand lever. This gave a difference score which was positive for an animal responding more often on the right lever and negative for an animal which responded predominately on the left.

\section{RESULTS}

In Fig. 1, total scores for the four daily sessions have been averaged for each group to give an overall display of the results. On Day 6 (not shown), the final day of training, the Right group scored $136 \mathrm{R}$ and $5 \mathrm{~L}$, the Left group scored $7 \mathrm{R}$ and $154 \mathrm{~L}$, and the Control group scored $9 \mathrm{R}$ and $5 \mathrm{~L}$. The derived scores were therefore $+131 \pm 49$ (SD), $-147 \pm 69$, and $+4 \pm 7$. By Day 17, the eleventh day of extinction, all groups had derived scores close to zero. On Day $18(0.32 \mu \mathrm{g} / \mathrm{rat})$ and Day $21(3.2 \mu \mathrm{g} / \mathrm{rat})$ the groups remained close to the zero value and no significant differences between the groups were observed. However, on Day $24(32 \mu \mathrm{g} / \mathrm{rat})$ a large selective increase in responding was seen in the Right group (+57 \pm 44 ) and the Left group $(-31 \pm 16)$ whereas the Control group remained near zero $(-3 \pm 12)$. Saline injections (Days 30 and 32) had little effect, but a second dose of $32 \mu \mathrm{g} / \mathrm{rat}$ of scopolamine hydrobromide on Day 39 induced a smaller but definite selective increase in responding. Five days later (Day 44) all groups were again near zero. A Mann-Whitney U test applied to the results of Days 17-44 for the Right and Left groups showed that the difference was statistically significant $(\mathrm{p}<.05)$ only on Day 24 (Dose $=32 \mu \mathrm{g}, \mathrm{p}=.004)$ and Day $39($ Dose $=32 \mu \mathrm{g}, \mathrm{p}=.008)$

\section{DISCUSSION}

It was reported as early as 1942 that certain conditioned responses could be extinguished and then restored by appropriate treatment (Gellhorn et al, 1942). Gellhorn and his co-workers conditioned animals to perform an active avoidance task, extinguished this behavior, and induced subsequent recovery with convulsions caused by pentylenetetrazole, electroshock, and insulin (Gellhorn, 1943; Kessler \& Gellhorn, 1943; Gellhorn \& Minatoya, 1943). The

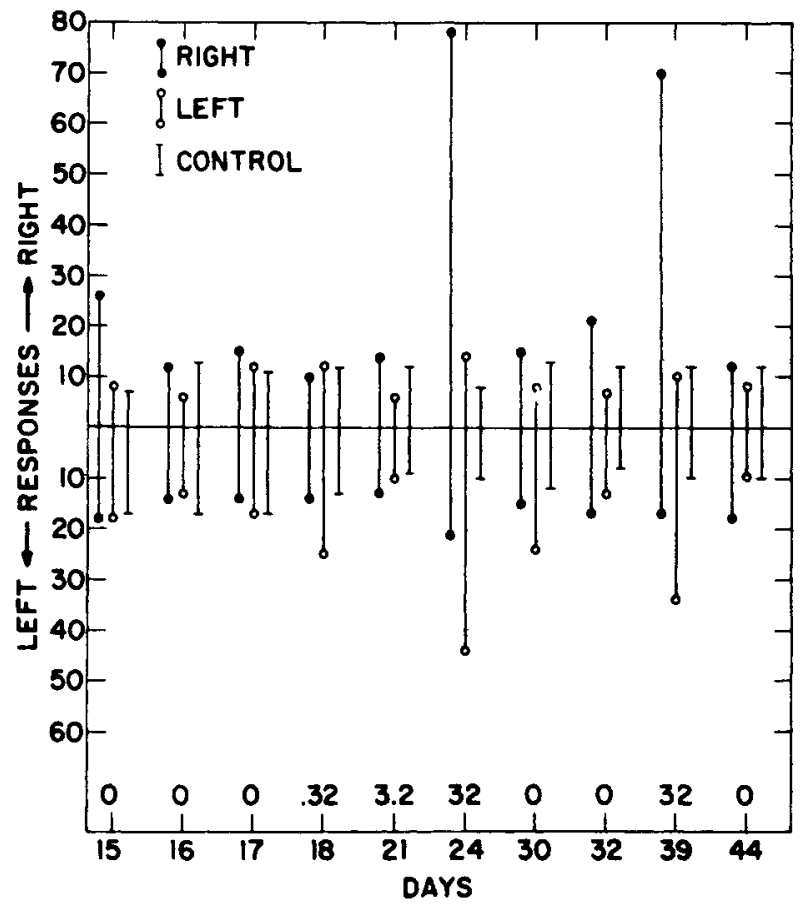

Fig. 1. Average group responses during extinction and testing. The numbers above each day indicate the dose of scopolamine hydrobromide in micrograms per rat. 
results reported here indicate that extinguished behavior following a different form of training. appetitive discrimination, can also be restored by pharmacological manipulation.

Hearst (1959) has reported results similar to these. Although he used stimulus rather than response discrimination, his results also showed a recovery of responding after extinction when scopolamine injections were given.

Leaf \& Muller (1966) have suggested that anticholinergic drugs such as scopolamine exert their effects by blocking the action of a muscarinic system in the CNS. On the basis of their results and the results presented here, this muscarinic system would be viewed as an inhibitory system which is activated during extinction and blocks the previously established stimulus-response chain.

\section{REFERENCES}

CARLTON, P. L. Cholinergic mechanisms in the control of behavior by the brain. Psychological Review, 1963, 70, 19-39.

GELLHORN, E. Studies on conditioned reactions and their clinical implications. Lancet, 1943, 63, 307-312.

GELLHORN, E \& MINATOYA, H. The effect of insulin hypoglycemia on conditioned reflexes. Journal of Neurophysiology, 1943, 6, 161-171.

GELLHORN, E., KESSLER, M., \& MINATOYA, H. Influence of Metrazol, insulin hypoglycemia, and electrically induced convulsions on reestablishment of inhibited conditioned reflexes. Proceedings of the Society for Experimental Biology and Medicine, 1942, 50, 260-262.

HEARST, E. Fffects of scopolamine on discriminated responding in the rat. Journal of Pharmacology. 1959, 126, 349-358.

HERRNSTEIN, R. J. Effects of scopolamine on a multiple schedule. Journal of the Experimental Analysis of Behavior, 1958, 1, 351-358.

KESSLER, M., \& TELLHORN, E. The effect of electrically and chenically induced convulsions on conditioned reflexes. American Journal of Psychiatry, 1943, 99, 687-691.

LEAF, R. C., \& MULLER, S. A. Central cholinergic response inhibition during massed free-operant and discrete-trial avoidance acquisition. Presented at the Fifth Meeting of the Collegium Internationale Neuro-Psychopharmacologicum, Washington, D. C., 1966.

NOTE

1. Contribution No. 1382. 